\title{
Food Additives, Gut Microbiota, and Irritable Bowel Syndrome: A Hidden Track
}

\author{
Emanuele Rinninella ${ }^{1, *(1)}$, Marco Cintoni ${ }^{2}\left(\mathbb{0}\right.$, Pauline Raoul ${ }^{3}(\mathbb{D})$, Antonio Gasbarrini ${ }^{4,5}$ \\ and Maria Cristina Mele ${ }^{3,5}$ (D) \\ 1 UOC di Nutrizione Clinica, Dipartimento di Scienze Mediche e Chirurgiche, Fondazione Policlinico \\ Universitario A. Gemelli IRCCS, Largo A. Gemelli 8, 00168 Rome, Italy \\ 2 Scuola di Specializzazione in Scienza dell'Alimentazione, Università di Roma Tor Vergata, Via Montpellier 1, \\ 00133 Rome, Italy; marco.cintoni@gmail.com \\ 3 UOSD di Nutrizione Avanzata in Oncologia, Dipartimento di Scienze Mediche e Chirurgiche, \\ Fondazione Policlinico Universitario A. Gemelli IRCCS, Largo A. Gemelli 8, 00168 Rome, Italy; \\ pauline.raoul1@gmail.com (P.R.); mariacristina.mele@unicatt.it (M.C.M.) \\ 4 UOC di Medicina Interna e Gastroenterologia, Dipartimento di Scienze Mediche e Chirurgiche, \\ Fondazione Policlinico Universitario A. Gemelli IRCCS, Largo A. Gemelli 8, 00168 Rome, Italy; \\ antonio.gasbarrini@unicatt.it \\ 5 Dipartimento di Medicina e Chirurgia Traslazionale, Università Cattolica Del Sacro Cuore, Largo F. Vito 1, \\ 00168 Rome, Italy \\ * Correspondence: emanuele.rinninella@unicatt.it; Tel.: +39-06-3015-5579
}

Received: 8 November 2020; Accepted: 24 November 2020; Published: 27 November 2020

\begin{abstract}
The interactions between diet, gut microbiota, and irritable bowel syndrome (IBS) have many complex mechanisms that are not fully understood. Food additives are one component of the modern human diet that deserves attention from science and government policies. This review aims at identifying the current knowledge about the impact of food additives on gut microbiota and their potential role in the development of IBS. To date, few data on the effect of food additives on gut microbiota in IBS patients are available. However, exposure to food additives could induce the dysbiosis and dysregulation of gut homeostasis with an alteration of the gut barrier and activation of the immune response. These microbial changes could exacerbate the gut symptoms associated with IBS, such as visceral pain, low-grade inflammation, and changes in bowel habits. Some additives (polyols) are excluded in the low fermentable oligo-, di- and monosaccharide, and polyol (FODMAP), diets for IBS patients. Even if most studies have been performed in animals, and human studies are required, many artificial sweeteners, emulsifiers, and food colorants could represent a potential hidden driver of IBS, through gut microbiota alterations. Consequently, food additives should be preventively avoided in the diet as well as dietary supplements for patients with IBS.
\end{abstract}

Keywords: food additives; IBS; microbiota; artificial sweeteners; polyols; emulsifiers; carboxymethylcellulose; polysorbate-80; titanium dioxide; food preservatives; personalized medicine

\section{Introduction}

The prevalence of irritable bowel syndrome (IBS) in Western countries ranges from $10 \%$ to $15 \%$, while lower prevalence rates have been reported in non-Western and developing countries [1]. To date, a specific biomarker for identifying IBS remains unknown, and its definition is entirely based on symptoms [2,3]. Patients with IBS typically experience abdominal discomfort or pain related to defecation with stool changes including diarrhea, constipation, or alternating constipation and diarrhea. Although the pathophysiology of IBS remains poorly understood, it has been suggested that genetic susceptibility, visceral hypersensitivity, food intolerance, altered gut-brain axis, gut dysmotility, 
immune dysfunction, and dysbiosis are the hallmark characteristics of IBS [4]. Diet is one of the key environmental factors that could induce gut dysbiosis directly influencing host homeostasis and immunological processes [5]. In this context, the interplay between diet and microbiota might have an essential role in IBS etiology [6].

Since the last few decades, the Westernization of eating habits has led to the increasing consumption of food additives being incorporated in almost all processed food [7]. Among them, salt is one of the most important natural additives used for food preservation. High salt consumption is well-known to alter gut microbiota composition and fecal short-chain fatty acids (SCFA) production [8], impacting the gut-immune axis through the modulation of T helper 17 cells [9] and promoting local and systemic tissue inflammation, which may lead to hypertension [10] and obesity [11]. On the other side, there are many other artificial substances added intentionally to food products to improve appearance, preserve flavor, and extend shelf life. The use of additives in food processing is regulated by the Food and Drug Administration (FDA) in the United States and the European Food Safety Authority (EFSA) in Europe. However, the outdated evaluation of the effect of food additives on human health is raising concerns. Currently, the EFSA is re-evaluating the safety of all food additives authorized for use before 20 January 2009, and final results should be obtained at the end of this year [12].

In this context, the effects of artificial food additives on microbiota have recently received much attention [13]. Indeed, emerging evidence suggests interactions between artificial food additives and microbiota, which may affect host health [14-16]. Furthermore, many preclinical studies have recently associated the increased and prolonged consumption of food additives with the development of colitis [17] and metabolic diseases [18,19], which is closely associated with detrimental effects on gut homeostasis.

This review aims to report and discuss the current knowledge about the impact of food additives on gut microbiota and their potential role in the development of IBS. We focused on some food additives, such as non-caloric sweeteners, polyols, emulsifiers, food colorants and preservatives.

\section{Methods}

A systematic literature search was performed across PubMed, Web of Science and Scopus databases from inception to September 2020. The relevant articles were identified and hand-searching was done to check the reference lists and find original as well as additional references. The search terms included "irritable bowel syndrome," "IBS", "microbiota", "microbiome", "artificial food additives", "artificial sweeteners", "polyols", "acesulfame potassium", "aspartame", "saccharin", "sucralose", "cyclamate", "neotame", "emulsifiers", "carboxymethyl cellulose", "polysorbate 80", "food coloring agents", "food preservatives", "benzoic acid", "sodium benzoate", "titanium dioxide", and "sodium nitrite".

\section{IBS, a Gut Microbiota-Related Disorder}

The onset of IBS-related symptoms often occurs during adolescence and affects more females than males [20]. The "Rome IV Criteria" is a diagnostic approach of IBS requiring that the patient has abdominal pain on average at least 1 day/week, and that pain is associated with two or more of the following characteristics: defecation, change in the frequency of stool, and change in the form (appearance) of the stool [21]. These criteria should be fulfilled for the previous 3 months, with symptoms onset at least 6 months prior to diagnosis [22]. Patients with IBS can be categorized into four major subtypes depending on the predominant stool pattern, including IBS with constipation (IBS-C), IBS with diarrhea (IBS-D), IBS with mixed stool types (IBS-M), and unclassified IBS [21]. Although the pathogenesis is still poorly understood, the underlying mechanisms that could lead to IBS include genetic and epigenetic influence, central nervous system alterations, and dietary and gastrointestinal influences such as gut microbiota alterations, gut motility changes, and low-grade mucosal inflammation and immune activation [23]. 
Many recent studies have suggested that gut microbiota are a key player in IBS pathogenesis [24-27]. The gut microbiota constitute a complex changing ecosystem that contains more than thousands of bacterial species and milliards of microorganisms mainly found in the distal small bowel and colon [28]. The anatomical gut barrier includes commensal gut microbiota, the mucus layer, and the intestinal epithelial monolayer. Abnormally increased permeability and alterations of the epithelial barrier and tight junctions were observed in some IBS patients [29]. Commensal bacteria are also key regulators of immune responses. Indeed, gut microbiota may regulate the production of $\mathrm{T}$ helper cells, resulting in inflammatory responses through the production of interleukins (IL) [30]. Specifically, Bifidobacterium infantis and Faecalibacterium Praustnizii could stimulate regulatory $\mathrm{T}$ cells (T reg) and the production of the anti-inflammatory cytokine IL-10. Interestingly, higher T cell levels isolated from blood and colonic biopsies were activated in IBS patients compared with healthy controls [31]. Furthermore, numerous studies, summarized in a recent systematic review [32], showed that low-grade mucosal inflammation could be associated with IBS. Moreover, increased levels of pro-inflammatory cytokines and higher numbers of mast cells are located close to enteric nerves in the gastrointestinal mucosa of IBS patients [33]. This condition could be associated with an activation of the immune system and an increased release of pro-inflammatory cytokines from isolated peripheral blood mononuclear cells, specifically in IBS-D patients [34].

Multiple studies investigated the associations between IBS and microbiota composition. Recently, a systematic review of studies compared the $\alpha$-diversity and gut microbiota variations between patients with IBS and healthy controls [35]. For most studies, the fecal samples of patients with IBS had a lower $\alpha$-diversity than healthy controls [36,37]. Patients with IBS had an increased Firmicutes:Bacteroidetes ratio, an increased abundance of Clostridia and Clostridiales, and a decreased abundance of Bacteroidia and Bacteroidales [36-38]. Given these findings, we can hypothesize that these increases or decreases of specific microbial groups could lead to microbial dysbiosis, a potential hallmark of IBS. Furthermore, various studies $[29,39]$ have reported an increased intestinal permeability in patients with diarrhea-predominant IBS (IBS-D).

As such, the gut microbiota are involved in the development of normal gut barrier integrity and gut immune system, but can also play a central role in the dysregulation of gut functions involved in IBS pathophysiology [40].

\section{Artificial Sweeteners, Gut Microbiota, and IBS}

Non-caloric artificial sweeteners (NAS) are synthetic non-nutritive sweeteners characterized by a higher sweetening intensity without increasing caloric intake [41]. NAS are mainly found in soft drinks, snack foods, sugar-free candies, and dairy products. The EFSA has approved various NAS such as acesulfame potassium (K) (E-950), aspartame (E-951), cyclamate (E-952), saccharin (E-954), sucralose (E-955) and neotame (E-961) [42].

\subsection{Artificial Sweeteners and Gut Microbiota Composition}

In rats, saccharin, sucralose and aspartame consumption were shown to be associated with an increase in Bacteroides spp and Clostridiales [18]. Palmnas et al. showed that low-dose aspartame consumption $(5-7 \mathrm{mg} / \mathrm{kg} / \mathrm{day}$ in drinking water for 8 weeks) in rats increased total bacteria, including Clostridium Leptum and Enterobacteriaceae [43]. Uebanso et al. found equivalent amounts of total bacteria, Firmicutes, Bacteroidetes, Bacteroides, Clostridium IV and Clostridium XIVa in male C57Bl/6J mice exposed to acesulfame $\mathrm{K}(15 \mathrm{mg} / \mathrm{kg} /$ day in drinking water for 8 weeks) and control groups [44]. Chi et al. [45] reported in male CD-1 mice exposed to neotame $(0.75 \mathrm{mg} / \mathrm{kg}$ body weight $/ \mathrm{day}$ for 4 weeks) a significant increase in Bacteroidetes and a significant decrease in Firmicutes compared with controls. The relative abundances of Ruminococcaceae, Lachnospiraceae such as Ruminococcus, Oscillospira, Dorea and Blautia were significantly lower in neotame-fed mice than in controls [45].

In humans, in a recent cross-sectional clinical study of 31 participants, an analysis of the fecal samples of adults consuming aspartame and acesulfame K did not report increased bacterial abundance, 
but decreased bacterial diversity, compared with those of non-consumers [46]. In seven participants consuming 1.7-33.2 mg/day of acesulfame $\mathrm{K}$ for 4 days, the median Bacteroidetes:Firmicutes ratio did not change, but bacterial diversity statistically differed compared with non-consumers [46].

According to a recent systematic review of human and animal studies [47], the consumption of artificial sweeteners, including acesulfame $\mathrm{K}$, aspartame, saccharin, sucralose, cyclamate, and neotame, is associated with gut dysbiosis [47]. Further studies and large randomized controlled trials are needed to investigate whether the intestinal microbiota variations reported in animals are present in humans.

\subsection{Effects of Artificial Sweeteners on Gut Functions and Metabolism}

Various studies explored the functional effect of NAS on the gut microbiota and host. They demonstrated an association of NAS consumption with increased insulin resistance and glucose intolerance $[18,43,48]$. Interestingly, Suez et al. showed in saccharin-consuming mice a significant increase in glycan degradation compared with control mice [18]. Given that gut bacteria fermented glycans into SCFAs [49], saccharin exposure could decrease SCFAs production. Recently, Farup et al. found that a NAS-enriched diet could be associated with a reduction in butyrate production in morbidly obese adults [50]. Butyrate has key anti-obesity effects induced by reducing appetite and activating brown adipose tissue via the gut-brain neural circuit [51]. As such, these results highlight the potential adverse effects of some NAS on the fermentation of glycans and the SCFAs' production, leading to metabolic disorders. Furthermore, Bian et al. [48] analyzed mouse livers after 6 months of saccharin administration, reporting significant liver inflammation with an elevated gene expression of TNF- $\alpha$ in the liver of saccharin-treated mice compared with control. TNF- $\alpha$ is a key cytokine in inflammation, mainly produced by macrophages induced by pathogen-associated molecular patterns (PAMPs), such as lipopolysaccharides (LPS). Moreover, the expression of TNF- $\alpha$ can activate NFkB pathways and induce cell damage and inflammatory responses.

\subsection{Impact of NAS Induced Microbiota Changes in IBS}

To date, to our knowledge, a direct link between NAS-induced microbiota changes and IBS has not been closely studied. However, some studies [52-54] have demonstrated a significant increase in Bacteroides in IBS-D patients. A recent systematic review of 24 clinical trials [55] showed microbiota variations associated with IBS, with an increase in Enterobacteriaceae, Lactobacillaceae and Bacteroides. As previously described, NAS consumption could increase Bacteroides [18] and Enterobacteriaceae [43] in rodent models. Enterobacteriaceae, such as Escherichia coli, Klebsiella spp. and Proteus spp., belong to the Proteobacteria phylum and are localized close to the mucosal epithelium. An infection by a pathogen [56], chemically induced colitis [57] or deficiencies in host immunity [58] could cause gut inflammation and could stimulate the growth of Enterobacteriaceae. Consequently, even if it is still difficult to identify specific intestinal bacteria associated with NAS consumption and IBS, it appears that NAS could be associated with dysbiosis, gut inflammation, and consequently symptoms associated with IBS subtypes.

\section{Polyols, Gut Microbiota and IBS}

Polyols are sugars. They are found naturally in some fruits, vegetables, and mushrooms. The FDA and EFSA approved different polyols such as erythritol (E-968), maltitol (E-965), sorbitol (E-420), and xylitol (E-967) for use as sweeteners. They are mainly used in chewing gum, candies, and beverages.

\subsection{Polyols and Gut Microbiota}

Xylitol (at the dosage of $40 \mathrm{mg} / \mathrm{kg}$ body weight/day) could decrease the abundance of fecal Bacteroidetes and Barnesiella, and stimulate the growth of Firmicutes and Prevotella in mice fed a high-fat diet [59]. As regards maltitol, a study of 40 human volunteers consuming low-energy chocolate containing $34.2 \mathrm{~g}$ of maltitol plus polydextrose found a significant increase in the abundance of fecal Bifidobacteria, Lactobacilli and SCFAs levels [60]. However, to date, the specific effects of maltitol on gut 
microbiota remain almost unexplored. Additionally, erythritol, a polyol completely non-fermentable by the human gut microbiota, is to date considered a safe additive [41,61]. Indeed, erythritol is absorbed through the small intestine with very low metabolism, and $90 \%$ of the substance is excreted unchanged in the urine [62]. Thus, a limited amount of erythritol reaches the colon and could potentially affect the gut microbiota [63]. As regards lactitol, an in vitro study showed-at the dosage of $2 \mathrm{mg} / \mathrm{L}$-that it could reduce Enterobacteriaceae abundance in feline fecal cultures [64]. In humans, fecal samples of 36 healthy adults consuming $2 \times 10 \mathrm{~g} / \mathrm{d}$ of lactitol or lactulose over 9 weeks were analyzed. Lactitol decreased bacterial populations of Bacteroides, Clostridium and Eubacterium compared with the lactulose group [65]. Another study by Finney et al. [66] analyzed fecal samples from 75 healthy adults before and after 7 days of consumption of low doses of lactitol ( $25 \mathrm{~g}$ tablets/day of milk chocolate containing $10 \mathrm{~g}$ sucrose:lactitol in ratios of 10:0, 5:5 or 0:10), showing that lactitol could increase the abundance of Bifidobacteria. Furthermore, a recent study showed that lactitol consumption in mice could enhance the growth of Akkermansia [67]. Akkermansia is a bacteria belonging to the Verrucomicrobia phylum, which improves the inflammatory response and reduces insulin resistance in obese and diabetic patients [68], protects the intestinal epithelial cells, and preserves the mucosal barrier function [69]. Thus, all these findings suggest that lactitol consumption could positively influence the gut microbiota's composition. Regarding sorbitol, a rat model study compared the effects of consumption of water plus sorbitol $10 \%$ with those of consumption of water plus fructooligosaccharides (FOS) $10 \%$ for 16 days [70]. The authors showed that both sorbitol and FOS exposures increased Lactobacillus reuteri cell numbers. Interestingly, sorbitol intake also maintained the levels of Lactobacillus sp. AD102, and significantly increased butyrate levels [70]. As such, in animal models, sorbitol could modify gut microbiota activity and contribute to gut homeostasis. However, further studies are needed to define the specific effects of sorbitol on the gut microbiota in humans.

\subsection{Impact of Polyols Induced Microbiota Changes in IBS}

No studies assessing the effects of polyols on the gut microbiota of patients with IBS were found. However, data are available on the effects of diet on the microbiota of IBS patients. Polyols are included in the category of the so-called "FODMAP" (fermentable oligo-, di- and monosaccharides, and polyols) diet. The term "FODMAP" was created by the Monash University in 2004 to define highly fermentable carbohydrates and polyols whose restriction would improve the outcome in IBS treatment [71]. In recent years, the FODMAP diet has become a valuable treatment option for IBS patients [72]. Halmos et al. studied the effects of FODMAP diet on the microbiota of 30 IBS patients reporting unchanged SCFA levels and a reduction of $47 \%$ of the total bacterial abundance in IBS patients following a low-FODMAP diet compared with those following a habitual diet [73]. Several other studies showed bacterial variations in patients following low-FODMAP diets, such as decreases in Akkermansia muciniphila [73], Clostridium cluster IV [73], Propionibacteriaceae [74], Ruminococcus gnavus [74] and Bifidobacteria [73,75,76] compared with patients following the control diet. Larger studies are needed to further understand the long-term effects of low-FODMAP diets, and especially the effects of polyols, such as sorbitol, on intestinal microbiota composition and IBS.

\section{Emulsifiers, Gut Microbiota and IBS}

Emulsifiers are amphiphilic molecules used either to facilitate processing or to improve the texture and shelf life of processed foods [77]. They are found in various processed foods such as sauces, puddings, margarine, and ice-creams. They are highly prevalent in the Western diet.

\subsection{Effect of Emulsifiers on Microbiota Composition}

Various studies investigated emulsifiers such as carboxymethylcellulose (CMC) and polysorbate-80 (P80). An animal study investigated the variations of gut microbiota in IL-10 gene-deficient mice fed with 2\% CMC solution for 3 weeks [78]. CMC-treated IL-10 gene-deficient mice reported an increase in total bacteria abundance in the ileum in treated mice compared with control mice. Specifically, 
a decrease in Eubacterium rectale in the ileum and jejunum and an increase in Bacteroides were found in mice treated with CMC. Chassaing et al. examined the direct impact of CMC on the microbiota using the mucosal simulator of the human intestinal microbial ecosystem (M-SHIME) model [79]. After CMC treatment for 13 weeks, the abundances of Proteobacteria and Firmicutes decreased significantly, and the abundance of Bacteroidetes increased. Similarly, the impact of P80 on gut microbiota composition was investigated. An animal study [17] showed that P80 intake had no significant effect on the total fecal bacteria in mice. However, a recent study [80] in mice treated with P80 (1.0\% drinking water solution for 8 weeks) demonstrated that P80 increased the Gamma-proteobacteria abundance, decreased the $\alpha$-diversity in the small intestine, and did not impact $\alpha$-diversity in the colon [80]. Viennois et al. [15] also showed that the relative abundances of Proteobacteria and Firmicutes in P80-treated mice decreased significantly, and the abundance of Bacteroidetes increased compared with controls. Glycerol monolaurate is another emulsifier recently investigated in C57BL/6 mice [81]. Glycerol monolaurate significantly changed the $\beta$-diversity with a decrease in Akkermansia muciniphila and Lupinus luteus, and an increase in Bacteroides acidifaciens and Escherichia coli [81]. Recently, Elmen et al. [82] studied the in vitro effects of glycerol monoacetate, glycerol monostearate, glycerol monolaurate, propylene glycol monostearate, and sodium stearoyl lactylate on fecal microbiota. Sodium stearoyl lactylate exposure $(0.025 \%$ water drinking solution $)$ reduced the abundances of Clostridiaceae, Lachnospiraceae and Ruminococaceae, and increased the abundances of Bacteroidaceae and Enterobacteriaceae [82]. To sum up, emulsifiers could directly alter the microbiota composition in mice/rats and in in vitro studies, but how these findings translate to humans needs further investigation.

\subsection{Emulsifiers and Gut Functions}

Chassaing et al. [17] showed the huge impact of P80 and CMC on fecal bacterial composition with an increase in Ruminicoccus gnavus and Akkermansia muciniphila; these changes have been associated with increased intestinal permeability, LPS levels, and flagellin circulating levels in mice as a result of a reduction in the intestinal mucus thickness. LPS represents the primary bacterial component encountered by the host immune system, while flagellin recently emerged as a potent immune activator, shaping both the innate and adaptive arms of immunity during microbial infections [83]. In germ-free mice receiving fecal transplantation from P80- and CMC-treated animals, a low-grade intestinal inflammation was observed [17]. Viennois et al. highlighted the role of these emulsifiers in intestinal inflammation-promoting colon carcinogenesis in mice [15]. Specifically, in mice exposed to P80 for 4 weeks, another study [84] reported the lower expression of mucin-2 with an increase of lipocalin-2 (LCN2), LPS, and flagellin, associated with a higher tumor incidence. An in vitro study confirmed these findings, showing an increase in the expression of the flagellin gene and LPS concentration in mice using the M-SHIME model and microbiota transplantation [79]. Furthermore, a recent rodent study [80] showed that CMC as well as P80 aggravated ileitis and increased the number of sulfide-producing bacteria. The high concentration of sulfide produced by sulfide-producing bacteria such as Bilophila wadsworthia may reduce disulfide bonds in the mucus, lysing the network of the polymeric protein MUC2 (oligomeric mucus gel-forming) [85]. MUC2 is secreted by goblet cells and has a key role in mucus layer stability and mucosal repair [86].

\subsection{Impact of Emulsifiers in IBS}

Mucosal barrier alterations could allow the passage of an increased abundance of luminal antigens which, in turn, activates the mucosal immune responses involved in diarrhea symptoms. As previously described above, emulsifiers could impact microbiota composition, including an increase in the sulfate-reducing bacteria that could exacerbate the hallmark symptoms of IBS. Appropriately, sulfate-reducing bacteria reduce sulfate to hydrogen sulfide $\left(\mathrm{H}_{2} \mathrm{~S}\right)$, which was recently recognized as a gaseous neuromodulator/neurotransmitter that modulates intestinal inflammation [87]. We can hypothesize that sulfate-reducing bacteria play a significant role in modulating visceral pain in IBS by 
producing $\mathrm{H}_{2} \mathrm{~S}$. As such, the consumption of emulsifiers by IBS patients could increase gut barrier permeability and intestinal inflammation, with an increase in LPS and flagellin and a decrease in MUC2. Holder et al. [88] confirmed that CMC and P80 exposure (drinking water containing CMC or P80 (1\%) for 12 weeks) could induce chronic intestinal inflammation, and alter gut microbiota composition in mice. Further work is needed to better understand the interplay between emulsifiers, gut microbiota, and epithelial mucosa in the pathogenesis of IBS.

\section{Food Colorants, Gut Microbiota, and IBS}

\subsection{Food Colorants and Gut Microbiota Composition}

Food colorants are mainly added to cheeses, sauces, skimmed milk, ice-creams, pastries, sweets, chocolates, and chewing-gum [89]. Titanium dioxide $\left(\mathrm{TiO}_{2}\right)$ is commonly used as a whitening or brightening agent in food products. $\mathrm{TiO}_{2}$ is referred to as E171 in Europe. In recent years, various studies have attempted to identify the impact of the oral consumption of $\mathrm{TiO}_{2}$ on gut microbiota composition in mice and humans. In mice treated with $\mathrm{TiO}_{2}$, a significant increase in Firmicutes [90] and a decrease in Bacteroidetes [91] were observed compared with controls. In particular, the abundance of Barnesiella, an anaerobic bacterium belonging to the Porphyromonadaceae family of the Bacteroidetes phylum, is significantly affected by $\mathrm{TiO}_{2}$ exposure ( $160 \mathrm{mg} / \mathrm{kg} /$ day for 28 days) [91]. Barnesiella could be a key protective intestinal bacterium, removing harmful bacteria from the intestine [92]. Mu et al. [93] found a significant decrease in Lactobacillus and Bifidobacterium in adult C57BL/6 female mice fed with a diet containing $0.1 \% \mathrm{TiO}_{2}$ for 3 months. Overall, animal studies found little effect of $\mathrm{TiO}_{2}$ on total microbial diversity. In vitro studies confirm this trend, showing that $\mathrm{TiO}_{2}$ might not dramatically reshape the human microbiota in a model of simplified human microbiota $[94,95]$. However, $\mathrm{TiO}_{2}$ 's impact on human microbiota over a long period has not been investigated.

\subsection{Food Colorants and Gut Functions}

Food colorants such as $\mathrm{TiO}_{2}$ could impact gut homeostasis. Indeed, recently, various in vitro and animal studies have demonstrated potential associations between $\mathrm{TiO}_{2}$ exposure and functional adverse effects on gut microbiota. In rats orally exposed for one week $\left(10 \mathrm{mg} / \mathrm{kg}\right.$ bw/day), $\mathrm{TiO}_{2}$ was detected in the immune cells of the Peyer's patches and regulatory $\mathrm{T}$ cells involved in inflammatory responses [96]. Specifically, after $\mathrm{TiO}_{2}$ exposure, the stimulation of immune cells isolated from Peyer's patches showed a decrease in T helper (Th)- 1 cells, an increased IFN- $\gamma$ secretion and an increased Th1/Th17 inflammatory response [96]. Ortega et al. went further, showing possible associations between E171 exposure and the development of intestinal diseases and colorectal cancer in rodents [97]. As regards possible mucus-related disorders, Talbot et al. showed in vitro that $\mathrm{TiO}_{2}$ could be captured by intestinal mucus; however, in vivo, two different $\mathrm{TiO}_{2}$ exposures $(0.1 \mathrm{mg} / \mathrm{kg}$ bw/day for 7 days and $10 \mathrm{mg} / \mathrm{kg} \mathrm{bw/day} \mathrm{for} 60$ days) did not cause variations in SCFAs levels [98]. Thus, given that SCFAs levels (in particular butyrate) are involved in mucin synthesis and mucus properties [99], in vivo, $\mathrm{TiO}_{2}$ exposure might not be associated with mucus barrier impairment. On the other hand, Pinget et al. [100] studied different dosages of $\mathrm{TiO}_{2}(2,10,50 \mathrm{mg} / \mathrm{kg}$ body weight/day) in mice and reported a reduction in SCFAs levels upon high-dose exposure, a decrease in mucus-related gene expression (MUC2), an increase in inflammatory response and an alteration of colonic crypt length. All these results highlight the need for further research to focus on the influence of $\mathrm{TiO}_{2}$ on microbiota and gut health.

\subsection{Impact of Food Colorants Induced Microbiota Changes in IBS}

As previously described, a recent study compared the effects of micro- $-\mathrm{TiO}_{2}$ and nano- $\mathrm{TiO}_{2}$ exposures on the murine intestinal tract, and found a significant bacterial decrease at both the family and genus level, including the Verrucomicrobiaceae family, Akkermansia genus, Porphyromonadaceae family, and Barnesiella genus. Interestingly, with the increase in exposure dose, the abundance of Barnesiella 
showed a significant dose-dependent decrease [91]. In parallel, Chen et al. [101] investigated the effect of a novel prebiotic blend (PB)—composed of fructooligosaccharides (FOS), galactooligosaccharides (GOS), inulin, and anthocyanin-on the development of IBS in mice. PB product in IBS mice could positively impact gut microbiota and modulate the immune response. Among gut microbiota changes, the level of the genus Barnesiella significantly decreased in the post-infectious IBS group, while Barnesiella increased in the PB pre-treatment group. Moreover, in the development of colitis in IL-10-/- mice, higher levels of Barnesiella are associated with lower activity levels of the disease [102]. These observations indicate that the genus Barnesiella could protect the intestinal tract from pathogen infections and play a key role in immunomodulation. Thus, all these findings suggest that dysbiosis due to the exposure to food colorants such as $\mathrm{TiO}_{2}$ could lead to microbiota dysbiosis, with variations of specific family and genus bacteria potentially involved in the pathogenesis of IBS.

\section{Preservatives, Gut Microbiota and IBS}

Food preservative additives are natural or synthetic substances that delay degradation in foods [103]. They can inhibit the growth of bacteria, fungi, or antioxidants, and inhibit the oxidation of food constituents. We focused on antimicrobial artificial preservatives, including sodium benzoate, sodium nitrate and sodium nitrite.

Although the benefits and safety of artificial preservatives are debated among food scientists and toxicologists, little is known about the effect of food preservatives on the microbiota. Only a recent study [104] found a significant impact of a mixture of sodium benzoate, sodium nitrite, and potassium sorbate consumption on mice colonized with a human microbiome, highlighting an overgrowth of Proteobacteria and a decrease in Clostridiales. The same authors further examined the susceptibility of gut microbiota to sodium benzoate, sodium nitrite and potassium sorbate, and their combinations, using a broth microdilution method [105]. They found that gut bacteria with anti-inflammatory properties, such as Clostridium tyrobutyricum or Lactobacillus paracasei, were significantly decreased compared with intestinal bacteria with proinflammatory or colitogenic properties, such as Bacteroides taiotaomicron or Enterococcus faecalis [105]. A randomized controlled trial showed that supplementation with Lactobacillus paracasei CNCM I-1572 for 18 weeks could modulate gut microbiota structure/function and reduce immune activation in IBS patients [106]. Indeed, after treatment, the IL15 levels significantly decreased compared with a placebo, suggesting a key role of Lactobacillus paracasei in the restoration of intestinal regulation and mucosal integrity [107].

\section{Conclusions: Food Additives, a Hidden Driver of IBS}

All these findings provide valuable insights regarding the potential impact of food additives on the gut microbiota composition potentially involved in the development of IBS (Figure 1). Indeed, exposure to food additives such as emulsifiers or artificial sweeteners alters the composition of gut microbiota in animal studies, even if further studies are needed in humans. Furthermore, polyols are among "FODMAPs", which are closely associated with IBS symptoms. Gut microbial diversity is a significant indicator of human health, and dysbiosis may be associated with gut dysfunction, leading to host inflammation and numerous non-communicable diseases, as well as IBS. Thus, food additives may substantially impact not only the composition of the microbiota but also its functions. On the other hand, IBS is clearly associated with an altered balance of gut microbiota composition, affecting gut functions.

Given that the consumption of ultra-processed food has increased over the last few decades and food additives are widely used in many such products, we can hypothesize that food additive-induced microbiota alterations might be one of the reasons for the growing incidence of IBS in Western countries. In daily life, IBS patients as consumers are regularly exposed to the food additives present in more than $50 \%$ of food products, as reported in a recent analysis of the co-occurrence of food additives on the French market [108]. Moreover, more than $10 \%$ of the food products contained five or more food additives. This "cocktail effect" remains overlooked, and further studies should focus on synergies between food additives. Another major issue is the lack of data about the daily intake of these 
substances. Indeed, although the food safety authorities determined an acceptable daily intake (ADI) for each category of food additives, the ingredient list offers little information for the amounts of additives in food products. Besides, we know that in toxicology, the relationship between the dose of the substance and the response is crucial. In this context, these issues highlight the strong need to understand how a sweetener, emulsifier, or a food preservative precisely impacts a phylum or family of gut bacteria, and to assess any potential synergistic effects among commonly used food additives on gut homeostasis.

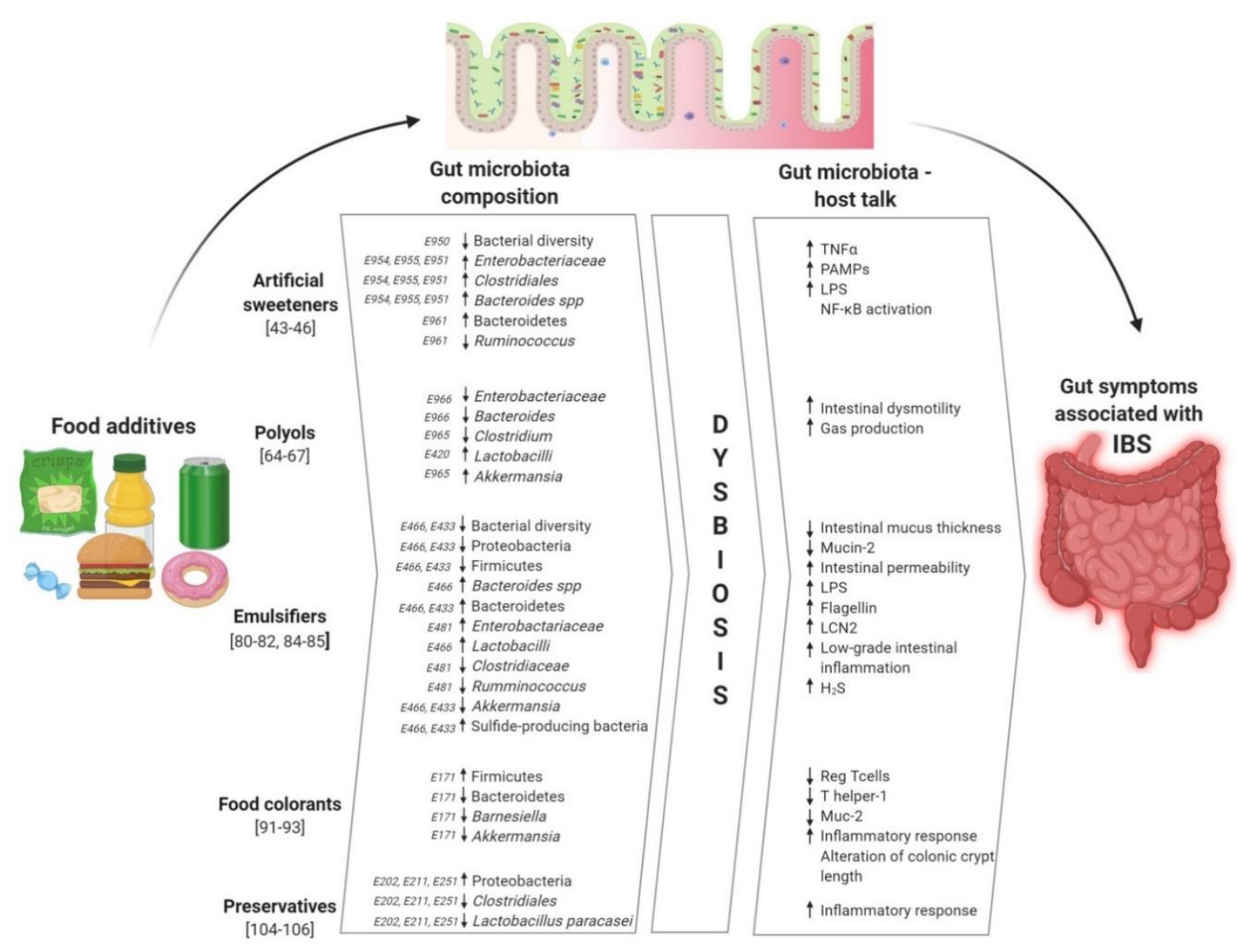

Figure 1. Food additives, gut microbiota, and irritable bowel syndrome (non-exhaustive list of food additives). Abbreviations: E171, titanium dioxide; E202, potassium sorbate; E211, sodium benzoate; E251, sodium nitrate; E420, sorbitol; E433, polysorbate 80; E466, carboxymethyl cellulose; E481, sodium stearoyl-2-lactylate; E950, acesulfame potassium; E951, aspartame; E954, saccharin; E955, sucralose; E961, neotame; E965, maltitol; E966, lactitol; LCN2, lipocalin-2; IBS, irritable bowel syndrome; LPS, lipopolysaccharides; Mucin-2, oligomeric mucus gel-forming protein encoded by the MUC2 gene; NFKB, nuclear factor-kappa B; PAMPs, pathogen associated molecular patterns; Reg T cells, regulatory $\mathrm{T}$ cells; TNF, tumor necrosis factor.

As such, to date, although food additives have not been studied specifically in patients with IBS, food additive consumption through the diet and dietary supplementation should be limited. Future studies are required to evaluate the effects of food additives on the human gut microbiota, and to characterize the direct/indirect underlying mechanisms involved in the pathogenesis of IBS.

Author Contributions: Conceptualization, E.R., and P.R.; methodology, P.R.; validation, M.C.M., and A.G.; investigation, M.C.; resources, M.C.; writing—original draft preparation, P.R.; writing-review and editing, E.R.; visualization, A.G.; supervision, M.C.M. All authors have read and agreed to the published version of the manuscript.

Funding: This research received no external funding. 
Conflicts of Interest: The authors declare no conflict of interest.

\section{References}

1. Lovell, R.M.; Ford, A.C. Global prevalence of and risk factors for irritable bowel syndrome: A meta-analysis. Clin. Gastroenterol. Hepatol. 2012, 10, 712-721. [CrossRef] [PubMed]

2. Lacy, B.E.; Patel, N.K. Rome criteria and a diagnostic approach to irritable bowel syndrome. J. Clin. Med. 2017, 6, 99. [CrossRef]

3. Rinninella, E.; Cintoni, M.; Mele, M.C.; Gasbarrini, A. Irritable Bowel Syndrome (IBS) and Non-Celiac Gluten Sensitivity (NCGS): Where Is the Culprit Hiding? Nutritional Tips for Gastroenterologists. Nutrients 2019, 11, 2499. [CrossRef] [PubMed]

4. Bellini, M.; Gambaccini, D.; Stasi, C.; Urbano, M.T.; Marchi, S.; Usai-Satta, P. Irritable bowel syndrome: A disease still searching for pathogenesis, diagnosis and therapy. World J. Gastroenterol. 2014, 20, 8807-8820. [PubMed]

5. Rinninella, E.; Raoul, P.; Cintoni, M.; Franceschi, F.; Miggiano, G.A.D.; Gasbarrini, A.; Mele, M.C. What is the Healthy Gut Microbiota Composition? A Changing Ecosystem across Age, Environment, Diet, and Diseases. Microorganisms 2019, 7, 14. [CrossRef]

6. Rinninella, E.; Cintoni, M.; Raoul, P.; Lopetuso, L.R.; Scaldaferri, F.; Pulcini, G.; Miggiano, G.A.D.; Gasbarrini, A.; Mele, M.C. Food Components and Dietary Habits: Keys for a Healthy Gut Microbiota Composition. Nutrients 2019, 11, 2393. [CrossRef]

7. Statovci, D.; Aguilera, M.; MacSharry, J.; Melgar, S. The Impact of Western Diet and Nutrients on the Microbiota and Immune Response at Mucosal Interfaces. Front. Immunol. 2017, 8, 838. [CrossRef]

8. Bier, A.; Braun, T.; Khasbab, R.; Di Segni, A.; Grossman, E.; Haberman, Y.; Leibowitz, A. A high salt diet modulates the gut microbiota and short chain fatty acids production in a salt-sensitive hypertension rat model. Nutrients 2018, 10, 1154. [CrossRef]

9. Wilck, N.; Matus, M.G.; Kearney, S.M.; Olesen, S.W.; Forslund, K.; Bartolomaeus, H.; Haase, S.; Mähler, A.; Balogh, A.; Markó, L.; et al. Salt-responsive gut commensal modulates TH17 axis and disease. Nature 2017, 551, 585-589. [CrossRef]

10. Smiljanec, K.; Lennon, S.L. Sodium, hypertension, and the gut: Does the gut microbiota go salty? Am. J. Physiol. Heart Circ. Physiol. 2019, 317, H1173-H1182. [CrossRef]

11. Seck, E.H.; Senghor, B.; Merhej, V.; Bachar, D.; Cadoret, F.; Robert, C.; Azhar, E.I.; Yasir, M.; Bibi, F.; Jiman-Fatani, A.A.; et al. Salt in stools is associated with obesity, gut halophilic microbiota and Akkermansia muciniphila depletion in humans. Int. J. Obes. 2019, 43, 862-871. [CrossRef] [PubMed]

12. Food Additive Re-Evaluations. Available online: https://www.efsa.europa.eu/en/topics/topic/food-additivere-evaluations (accessed on 20 November 2020).

13. Gultekin, F.; Oner, M.E.; Savas, H.B.; Dogan, B. Food additives and microbiota. North Clin. Istanb. 2019, 7, 192-200. [CrossRef] [PubMed]

14. Laudisi, F.; Stolfi, C.; Monteleone, G. Impact of Food Additives on Gut Homeostasis. Nutrients 2019, 11, 2334. [CrossRef] [PubMed]

15. Viennois, E.; Merlin, D.; Gewirtz, A.T.; Chassaing, B. Dietary emulsifier-induced low-grade inflammation promotes colon carcinogenesis. Cancer Res. 2017, 77, 27-40. [CrossRef] [PubMed]

16. Rodriguez-Palacios, A.; Harding, A.; Menghini, P.; Himmelman, C.; Retuerto, M.; Nickerson, K.P.; Lam, M.; Croniger, C.M.; McLean, M.H.; Durum, S.K.; et al. The Artificial Sweetener Splenda Promotes Gut Proteobacteria, Dysbiosis, and Myeloperoxidase Reactivity in Crohn's Disease-Like Ileitis. Inflamm. Bowel Dis. 2018, 24, 1005-1020. [CrossRef] [PubMed]

17. Chassaing, B.; Koren, O.; Goodrich, J.K.; Poole, A.C.; Srinivasan, S.; Ley, R.E.; Gewirtz, A.T. Dietary emulsifiers impact the mouse gut microbiota promoting colitis and metabolic syndrome. Nature 2015, 519, 92-96. [CrossRef]

18. Ruiz, P.A.; Morón, B.; Becker, H.M.; Lang, S.; Atrott, K.; Spalinger, M.R.; Scharl, M.; Wojtal, K.A.; Fischbeck-Terhalle, A.; Frey-Wagner, I.; et al. Titanium dioxide nanoparticles exacerbate DSS-induced colitis: Role of the NLRP3 inflammasome. Gut 2017, 66, 1216-1224. [CrossRef] 
19. Suez, J.; Korem, T.; Zeevi, D.; Zilberman-Schapira, G.; Thaiss, C.A.; Maza, O.; Israeli, D.; Zmora, N.; Gilad, S.; Weinberger, A.; et al. Artificial sweeteners induce glucose intolerance by altering the gut microbiota. Nature 2014, 514, 181-186. [CrossRef]

20. Olivier-Van Stichelen, S.; Rother, K.I.; Hanover, J.A. Maternal Exposure to Non-nutritive Sweeteners Impacts Progeny's Metabolism and Microbiome. Front. Microbiol. 2019, 10, 1360. [CrossRef]

21. Canavan, C.; West, J.; Card, T. The epidemiology of irritable bowel syndrome. Clin. Epidemiol. 2014, 6,71-80. [CrossRef]

22. Lacy, B.E.; Moreau, J.C. Diarrhea-predominant irritable bowel syndrome: Diagnosis, etiology, and new treatment considerations. J. Am. Assoc. Nurse Pract. 2016, 28, 393-404. [CrossRef] [PubMed]

23. Drossman, D.A. Functional gastrointestinal disorders: History, pathophysiology, clinical features and Rome IV. Gastroenterology 2016, 150, 1262-1279. [CrossRef]

24. Carroll, I.M.; Chang, Y.H.; Park, J.; Sartor, R.B.; Ringel, Y. Luminal and mucosal-associated intestinal microbiota in patients with diarrhea-predominant irritable bowel syndrome. Gut Pathog. 2010, 2, 19. [CrossRef] [PubMed]

25. Carroll, I.M.; Ringel-Kulka, T.; Siddle, J.P.; Ringel, Y. Alterations in composition and diversity of the intestinal microbiota in patients with diarrhea-predominant irritable bowel syndrome. Neurogastroenterol. Motil. 2012, 24, 521-530. [CrossRef] [PubMed]

26. Durbán, A.; Abellán, J.J.; Jiménez-Hernández, N.; Artacho, A.; Garrigues, V.; Ortiz, V.; Ponce, J.; Latorre, A.; Moya, A. Instability of the faecal microbiota in diarrhoea-predominant irritable bowel syndrome. FEMS Microbiol. Ecol. 2013, 86, 581-589. [CrossRef] [PubMed]

27. Malinen, E.; Rinttila, T.; Kajander, K.; Mättö, J.; Kassinen, A.; Krogius, L.; Saarela, M.; Korpela, R.; Palva, A. Analysis of the fecal microbiota of irritable bowel syndrome patients and healthy controls with real-time PCR. Am. J. Gastroenterol. 2005, 100, 373-382. [CrossRef] [PubMed]

28. Guarner, F.; Malagelada, J.R. Gut flora in health and disease. Lancet 2003, 361, 512-519. [CrossRef]

29. Dunlop, S.P.; Hebden, J.; Campbell, E.; Naesdal, J.; Olbe, L.; Perkins, A.C.; Spiller, R.C. Abnormal intestinal permeability in subgroups of diarrhea-predominant irritable bowel syndromes. Am. J. Gastroenterol. 2006, 101, 1288-1294. [CrossRef]

30. O'Mahony, S.M.; Dinan, T.G.; Cryan, J.F. The gut microbiota as a key regulator of visceral pain. Pain. 2017, 158 (Suppl. 1), S19-S28. [CrossRef]

31. Ohman, L.; Isaksson, S.; Lindmark, A.C.; Posserud, I.; Stotzer, P.O.; Strid, H.; Sjövall, H.; Simrén, M. T-cell activation in patients with irritable bowel syndrome. Am. J. Gastroenterol. 2009, 104, 1205-1212. [CrossRef]

32. Holtmann, G.J.; Ford, A.C.; Talley, N.J. Pathophysiology of irritable bowel syndrome. Lancet Gastroenterol. Hepatol. 2016, 1, 133-146. [CrossRef]

33. Gwee, K.A.; Collins, S.M.; Read, N.W.; Rajnakova, A.; Deng, Y.; Graham, J.C.; McKendrick, M.W.; Moochhala, S.M. Increased rectal mucosal expression of interleukin $1 \beta$ in recently acquired post-infectious irritable bowel syndrome. Gut 2003, 52, 523-526. [CrossRef] [PubMed]

34. Liebregts, T.; Adam, B.; Bredack, C.; Röth, A.; Heinzel, S.; Lester, S.; Downie-Doyle, S.; Smith, E.; Drew, P.; Talley, N.J. Immune activation in patients with irritable bowel syndrome. Gastroenterology 2007, 132, 913-920. [CrossRef] [PubMed]

35. Duan, R.; Zhu, S.; Wang, B.; Duan, L. Alterations of gut microbiota in patients with irritable bowel syndrome based on 16s rrna-targeted sequencing: A systematic review. Clin. Transl. Gastroenterol. 2019, 10, e00012. [CrossRef] [PubMed]

36. Liu, H.N.; Wu, H.; Chen, Y.Z.; Chen, Y.J.; Shen, X.Z.; Liu, T.T. Altered molecular signature of intestinal microbiota in irritable bowel syndrome patients compared with healthy controls: A systematic review and meta-analysis. Dig. Liver Dis. 2017, 49, 331-337. [CrossRef]

37. Zeber-Lubecka, N.; Kulecka, M.; Ambrozkiewicz, F.; Paziewska, A.; Goryca, K.; Karczmarski, J.; Rubel, T.; Wojtowicz, W.; Mlynarz, P.; Marczak, L.; et al. Limited prolonged effects of rifaximin treatment on irritable bowel syndrome-related differences in the fecal microbiome and metabolome. Gut Microbes 2016, 7, 397-413. [CrossRef]

38. Pozuelo, M.; Panda, S.; Santiago, A.; Mendez, S.; Accarino, A.; Santos, J.; Guarner, F.; Azpiroz, F.; Manichanh, C. Reduction of butyrate- and methane-producing microorganisms in patients with irritable bowel syndrome. Sci. Rep. 2015, 5, 12693. [CrossRef] 
39. Zhou, Q.; Zhang, B.; Verne, G.N. Intestinal membrane permeability and hypersensitivity in the irritable bowel syndrome. Pain 2009, 146, 41-46. [CrossRef]

40. Camilleri, M.; Madsen, K.; Spiller, R.; Van Meerveld, B.G.; Verne, G.N. Intestinal barrier function in health and gastrointestinal disease. Neurogastroenterol. Motil. 2012, 24, 503-512. [CrossRef]

41. Carocho, M.; Barreiro, M.F.; Morales, P.; Ferreira, I.C.F.R. Adding molecules to food, pros and cons: A review on synthetic and natural food additives. Compr. Rev. Food Sci. Food Saf. 2014, 13, 377-399. [CrossRef]

42. Commission Regulation (EU) No 1129/2011 of 11 November 2011 Amending Annex II to Regulation (EC) No 1333/2008 of the European Parliament and of the Council by Establishing a Union List of Food Additives (Text with EEA Relevance). Available online: https://publications.europa.eu/en/publication-detail/ -/publication/28cb4a37-b40e-11e3-86f9-01aa75ed71a1/language-en (accessed on 27 October 2020).

43. Palmnäs, M.S.; Cowan, T.E.; Bomhof, M.R.; Su, J.; Reimer, R.A.; Vogel, H.J.; Hittel, D.S.; Shearer, J. Low-dose aspartame consumption differentially affects gut microbiota-host metabolic interactions in the diet-induced obese rat. PLoS ONE 2014, 9, e109841. [CrossRef] [PubMed]

44. Uebanso, T.; Ohnishi, A.; Kitayama, R.; Yoshimoto, A.; Nakahashi, M.; Shimohata, T.; Mawatari, K.; Takahashi, A. Effects of Low-Dose Non-Caloric Sweetener Consumption on Gut Microbiota in Mice. Nutrients 2017, 9, 560. [CrossRef] [PubMed]

45. Chi, L.; Bian, X.; Gao, B.; Tu, P.; Lai, Y.; Ru, H.; Lu, K. Effects of the Artificial Sweetener Neotame on the Gut Microbiome and Fecal Metabolites in Mice. Molecules 2018, 23, 367. [CrossRef] [PubMed]

46. Frankenfeld, C.L.; Sikaroodi, M.; Lamb, E.; Shoemaker, S.; Gillevet, P.M. High-intensity sweetener consumption and gut microbiome content and predicted gene function in a cross-sectional study of adults in the United States. Ann. Epidemiol. 2015, 25, 736-742. [CrossRef] [PubMed]

47. Cao, Y.; Liu, H.; Qin, N.; Ren, X.; Zhu, B.; Xia, X. Impact of food additives on the composition and function of gut microbiota: A review. Trends Food Sci. Technol. 2020, 99, 295-310. [CrossRef]

48. Bian, X.; Tu, P.; Chi, L.; Gao, B.; Ru, H.; Lu, K. Saccharin induced liver inflammation in mice by altering the gut microbiota and its metabolic functions. Food Chem. Toxicol. 2017, 107, 530-539. [CrossRef]

49. Koropatkin, N.M.; Cameron, E.A.; Martens, E.C. How glycan metabolism shapes the human gut microbiota. Nat. Rev. Microbiol. 2012, 10, 323-335. [CrossRef]

50. Farup, P.G.; Lydersen, S.; Valeur, J. Are Nonnutritive Sweeteners Obesogenic? Associations between diet, faecal microbiota, and short-chain fatty acids in morbidly obese subjects. J. Obes. 2019, 2019, 4608315. [CrossRef]

51. Li, Z.; Yi, C.X.; Katiraei, S.; Kooijman, S.; Zhou, E.; Chung, C.K.; Gao, Y.; van den Heuvel, J.K.; Meijer, O.C.; Berbée, J.F.P.; et al. Butyrate reduces appetite and activates brown adipose tissue via the gut-brain neural circuit. Gut 2018, 67, 1269-1279. [CrossRef]

52. Liu, Y.; Zhang, L.; Wang, X.; Zhang, J.; Jiang, R.; Wang, X.; Wang, K.; Liu, Z.; Xia, Z.; Xu, Z.; et al. Similar fecal microbiota signatures in patients with diarrhea-predominant irritable bowel syndrome and patients with depression. Clin. Gastroenterol. Hepatol. 2016, 14, 1602-1611. [CrossRef]

53. Shukla, R.; Ghoshal, U.; Dhole, T.N.; Ghoshal, U.C. Fecal Microbiota in Patients with Irritable Bowel Syndrome Compared with Healthy Controls Using Real-Time Polymerase Chain Reaction: An Evidence of Dysbiosis. Dig Dis. Sci. 2015, 60, 2953-2962. [CrossRef] [PubMed]

54. Zhong, W.; Lu, X.; Shi, H.; Zhao, G.; Song, Y.; Wang, Y.; Zhang, J.; Jin, Y.; Wang, S. Distinct Microbial Populations Exist in the Mucosa-associated Microbiota of Diarrhea Predominant Irritable Bowel Syndrome and Ulcerative Colitis. J. Clin. Gastroenterol. 2019, 53, 660-672. [CrossRef] [PubMed]

55. Pittayanon, R.; Lau, J.T.; Yuan, Y.; Leontiadis, G.I.; Tse, F.; Surette, M.; Moayyedi, P. Gut Microbiota in Patients With Irritable Bowel Syndrome-A Systematic Review. Gastroenterology 2019, 157, 97-108. [CrossRef] [PubMed]

56. Lupp, C.; Robertson, M.L.; Wickham, M.E.; Sekirov, I.; Champion, O.L.; Gaynor, E.C.; Finlay, B.B. Host-Mediated Inflammation Disrupts the Intestinal Microbiota and Promotes the Overgrowth of Enterobacteriaceae. Cell Host Microbe 2007, 2, 119-129. [CrossRef] [PubMed]

57. Zeng, M.Y.; Cisalpino, D.; Varadarajan, S.; Hellman, J.; Warren, H.S.; Cascalho, M.; Inohara, N.; Núñez, G. Gut Microbiota-Induced Immunoglobulin G Controls Systemic Infection by Symbiotic Bacteria and Pathogens. Immunity 2016, 44, 647-658. [CrossRef] [PubMed]

58. Garrett, W.S.; Gallini, C.A.; Yatsunenko, T.; Michaud, M.; Dubois, A.; Delaney, M.L.; Punit, S.; Karlsson, M.; Bry, L.; Glickman, J.N.; et al. Enterobacteriaceae Act in Concert with the Gut Microbiota to Induce Spontaneous and Maternally Transmitted Colitis. Cell Host Microbe 2010, 8, 292-300. [CrossRef] [PubMed] 
59. Uebanso, T.; Kano, S.; Yoshimoto, A.; Naito, C.; Shimohata, T.; Mawatari, K.; Takahashi, A. Effects of Consuming Xylitol on Gut Microbiota and Lipid Metabolism in Mice. Nutrients 2017, 9, 756. [CrossRef]

60. Beards, E.; Tuohy, K.; Gibson, G. A human volunteer study to assess the impact of confectionery sweeteners on the gut microbiota composition. Br. J. Nutr. 2010, 104, 701-708. [CrossRef]

61. Arrigoni, E.; Brouns, F.; Amadò, R. Human gut microbiota does not ferment erythritol. Br. J. Nutr. 2005, 94, 643-646. [CrossRef]

62. Grembecka, M. Sugar alcohols-Their role in the modern world of sweeteners: A review. Eur. Food Res. Technol. 2015, 241,1-14. [CrossRef]

63. Ruiz-Ojeda, F.J.; Plaza-Díaz, J.; Sáez-Lara, M.J.; Gil, A. Effects of Sweeteners on the Gut Microbiota: A Review of Experimental Studies and Clinical Trials. Adv. Nutr. 2019, 10, S31-S48. [CrossRef] [PubMed]

64. Pinna, C.; Stefanelli, C.; Biagi, G. In Vitro effect of dietary protein level and nondigestible oligosaccharides on feline fecal microbiota1. J. Anim. Sci. 2014, 92, 5593-5602. [CrossRef] [PubMed]

65. Ballongue, J.; Schumann, C.; Quignon, P. Effects of lactulose and lactitol on colonic microflora and enzymatic activity. Scand. J. Gastroenterol. Suppl. 1997, 222, 41-482. [CrossRef]

66. Finney, M.; Smullen, J.; Foster, H.A.; Brokx, S.; Storey, D.M. Effects of low doses of lactitol on faecal microflora, $\mathrm{pH}$, short chain fatty acids and gastrointestinal symptomology. Eur. J. Nutr. 2007, 46, 307-314. [CrossRef] [PubMed]

67. Wang, Y.-N.; Meng, X.-C.; Dong, Y.-F.; Zhao, X.-H.; Qian, J.-M.; Wang, H.-Y.; Li, J.-N. Effects of probiotics and prebiotics on intestinal microbiota in mice with acute colitis based on 16S rRNA gene sequencing. Chin. Med. J. 2019, 132, 1833-1842. [CrossRef] [PubMed]

68. Hansen, C.H.F.; Krych, L.; Nielsen, D.S.; Vogensen, F.K.; Hansen, L.H.; Sørensen, S.J.; Buschard, K.; Hansen, A.K. Early life treatment with vancomycin propagates Akkermansia muciniphila and reduces diabetes incidence in the NOD mouse. Diabetologia 2012, 55, 2285-2294. [CrossRef] [PubMed]

69. Reunanen, J.; Kainulainen, V.; Huuskonen, L.; Ottman, N.; Belzer, C.; Huhtinen, H.; De Vos, W.M.; Satokari, R. Akkermansia muciniphila Adheres to Enterocytes and Strengthens the Integrity of the Epithelial Cell Layer. Appl. Environ. Microbiol. 2015, 81, 3655-3662. [CrossRef]

70. Sarmiento-Rubiano, L.A.; Zuñiga, M.; Perez-Martinez, G.; Yebra, M.J. Dietary supplementation with sorbitol results in selective enrichment of lactobacilli in rat intestine. Res. Microbiol. 2007, 158, 694-701. [CrossRef]

71. Gibson, P.R. History of the low FODMAP diet. J. Gastroenterol. Hepatol. 2017, 32, 5-7. [CrossRef]

72. Catassi, G.; Lionetti, M.E.; Gatti, S.; Catassi, C. The Low FODMAP Diet: Many Question Marks for a Catchy Acronym. Nutrients 2017, 9, 292. [CrossRef]

73. Halmos, E.P.; Power, V.A.; Shepherd, S.J.; Gibson, P.R.; Muir, J.G. A diet low in FODMAPs reduces symptoms of irritable bowel syndrome. Gastroenterology 2014, 146, 67-75. [CrossRef] [PubMed]

74. McIntosh, K.; Reed, D.E.; Schneider, T.; Dang, F.; Keshteli, A.H.; De Palma, G.; Madsen, K.; Bercik, P.; Vanner, S. FODMAPs alter symptoms and the metabolome of patients with IBS: A randomised controlled trial. Gut 2016, 66, 1241-1251. [CrossRef] [PubMed]

75. Staudacher, H.M.; Lomer, M.C.E.; Anderson, J.L.; Barrett, J.S.; Muir, J.G.; Irving, P.M.; Whelan, K. Fermentable Carbohydrate Restriction Reduces Luminal Bifidobacteria and Gastrointestinal Symptoms in Patients with Irritable Bowel Syndrome. J. Nutr. 2012, 142, 1510-1518. [CrossRef] [PubMed]

76. Staudacher, H.M.; Lomer, M.C.; Farquharson, F.; Louis, P.; Fava, F.; Franciosi, E.; Scholz, M.; Tuohy, K.M.; Lindsay, J.O.; Irving, P.M.; et al. A Diet Low in FODMAPs Reduces Symptoms in Patients With Irritable Bowel Syndrome and A Probiotic Restores Bifidobacterium Species: A Randomized Controlled Trial. Gastroenterology 2017, 153, 936-947. [CrossRef] [PubMed]

77. Halmos, E.P.; Mack, A.; Gibson, P.R. Review article: Emulsifiers in the food supply and implications for gastrointestinal disease. Aliment. Pharmacol. Ther. 2019, 49, 41-50. [CrossRef] [PubMed]

78. Swidsinski, A.; Ung, V.; Sydora, B.C.; Loening-Baucke, V.; Doerffel, Y.; Verstraelen, H.; Fedorak, R.N. Bacterial Overgrowth and Inflammation of Small Intestine After Carboxymethylcellulose Ingestion in Genetically Susceptible Mice. Inflamm. Bowel Dis. 2009, 15, 359-364. [CrossRef]

79. Chassaing, B.; Van De Wiele, T.; De Bodt, J.; Marzorati, M.; Gewirtz, A.T. Dietary emulsifiers directly alter human microbiota composition and gene expression ex vivo potentiating intestinal inflammation. Gut 2017, 66, 1414-1427. [CrossRef] 
80. Furuhashi, H.; Higashiyama, M.; Okada, Y.; Kurihara, C.; Wada, A.; Horiuchi, K.; Hanawa, Y.; Mizoguchi, A.; Nishii, S.; Inaba, K.; et al. Dietary emulsifier polysorbate-80-induced small-intestinal vulnerability to indomethacin-induced lesions via dysbiosis. J. Gastroenterol. Hepatol. 2020, 35, 110-117. [CrossRef]

81. Jiang, Z.; Zhao, M.; Zhang, H.; Zengliang, J.; Liu, M.; Feng, F. Antimicrobial Emulsifier-Glycerol Monolaurate Induces Metabolic Syndrome, Gut Microbiota Dysbiosis, and Systemic Low-Grade Inflammation in Low-Fat Diet Fed Mice. Mol. Nutr. Food Res. 2018, 62, 62. [CrossRef]

82. Elmén, L.; Zlamal, J.E.; Scott, D.A.; Lee, R.B.; Chen, D.J.; Colas, A.R.; Rodionov, D.A.; Peterson, S.N. Dietary Emulsifier Sodium Stearoyl Lactylate Alters Gut Microbiota in vitro and Inhibits Bacterial Butyrate Producers. Front. Microbiol. 2020, 11, 892. [CrossRef]

83. Hajam, I.A.; Dar, P.A.; Shahnawaz, I.; Jaume, J.C.; Lee, J.H. Bacterial flagellin-A potent immunomodulatory agent. Exp. Mol. Med. 2017, 49, e373. [CrossRef] [PubMed]

84. Singh, R.K. Food Additive P-80 Impacts Mouse Gut Microbiota Promoting Intestinal Inflammation, Obesity and Liver Dysfunction. SOJ Microbiol. Infect. Dis. 2016, 4, 10. [CrossRef] [PubMed]

85. Ijssennagger, N.; Van Der Meer, R.; Van Mil, S.W. Sulfide as a Mucus Barrier-Breaker in Inflammatory Bowel Disease? Trends Mol. Med. 2016, 22, 190-199. [CrossRef] [PubMed]

86. Johansson, M.E.V.; Phillipson, M.; Petersson, J.; Velcich, A.; Holm, L.; Hansson, G.C. The inner of the two Muc2 mucin-dependent mucus layers in colon is devoid of bacteria. Proc. Natl. Acad. Sci. USA 2008, 105, 15064-15069. [CrossRef]

87. Medani, M.; Collins, D.; Docherty, N.G.; Baird, A.W.; O'connell, P.R.; Winter, D.C. Emerging role of hydrogen sulfide in colonic physiology and pathophysiology. Inflamm. Bowel Dis. 2011, 17, 1620-1625. [CrossRef]

88. Holder, M.K.; Peters, N.; Whylings, J.; Fields, C.T.; Gewirtz, A.T.; Chassaing, B.; De Vries, G.J. Dietary emulsifiers consumption alters anxiety-like and social-related behaviors in mice in a sex-dependent manner. Sci. Rep. 2019, 9, 172. [CrossRef]

89. Oplatowska-Stachowiak, M.; Elliott, C.T. Food colors: Existing and emerging food safety concerns. Crit. Rev. Food Sci. Nutr. 2017, 57, 524-548. [CrossRef]

90. Zhang, S.; Jiang, X.; Cheng, S.; Fan, J.; Qin, X.; Wang, T.; Zhang, Y.; Zhang, J.; Qiu, Y.; Qiu, J.; et al. Titanium dioxide nanoparticles via oral exposure leads to adverse disturbance of gut microecology and locomotor activity in adult mice. Arch. Toxicol. 2020, 94, 1173-1190. [CrossRef]

91. Yan, J.; Wang, D.; Li, K.; Chen, Q.; Lai, W.; Tian, L.; Lin, B.; Tan, Y.; Liu, X.; Xi, Z. Toxic effects of the food additives titanium dioxide and silica on the murine intestinal tract: Mechanisms related to intestinal barrier dysfunction involved by gut microbiota. Environ. Toxicol. Pharmacol. 2020, 80, 103485. [CrossRef]

92. Ubeda, C.; Bucci, V.; Caballero, S.; Djukovic, A.; Toussaint, N.C.; Equinda, M.; Lipuma, L.; Ling, L.; Gobourne, A.; No, D.; et al. Intestinal Microbiota Containing Barnesiella Species Cures Vancomycin-Resistant Enterococcus faecium Colonization. Infect. Immun. 2013, 81, 965-973. [CrossRef]

93. Mu, W.; Wang, Y.; Huang, C.; Fu, Y.; Li, J.; Wang, H.; Jia, X.; Ba, Q. Effect of Long-Term Intake of Dietary Titanium Dioxide Nanoparticles on Intestine Inflammation in Mice. J. Agric. Food Chem. 2019, 67, 9382-9389. [CrossRef] [PubMed]

94. Dudefoi, W.; Moniz, K.; Allen-Vercoe, E.; Ropers, M.-H.; Walker, V.K. Impact of food grade and nano-TiO 2 particles on a human intestinal community. Food Chem. Toxicol. 2017, 106, 242-249. [CrossRef] [PubMed]

95. Waller, T.; Chen, C.; Walker, S.L. Food and Industrial Grade Titanium Dioxide Impacts Gut Microbiota. Environ. Eng. Sci. 2017, 34, 537-550. [CrossRef]

96. Bettini, S.; Boutet-Robinet, E.; Cartier, C.; Coméra, C.; Gaultier, E.; Dupuy, J.; Naud, N.; Taché, S.; Grysan, P.; Reguer, S.; et al. Food-grade TiO2 impairs intestinal and systemic immune homeostasis, initiates preneoplastic lesions and promotes aberrant crypt development in the rat colon. Sci. Rep. 2017, 7, 40373. [CrossRef] [PubMed]

97. Urrutia-Ortega, I.M.; Garduño-Balderas, L.G.; Delgado-Buenrostro, N.L.; Freyre-Fonseca, V.; Flores-Flores, J.O.; González-Robles, A.; Pedraza-Chaverri, J.; Hernández-Pando, R.; Rodriguez-Sosa, M.; León-Cabrera, S.; et al. Food-grade titanium dioxide exposure exacerbates tumor formation in colitis associated cancer model. Food Chem. Toxicol. 2016, 93, 20-31. [CrossRef] [PubMed]

98. Talbot, P.; Radziwill-Bienkowska, J.M.; Kamphuis, J.B.J.; Steenkeste, K.; Bettini, S.; Robert, V.; Noordine, M.-L.; Mayeur, C.; Gaultier, E.; Langella, P.; et al. Food-grade TiO2 is trapped by intestinal mucus in vitro but does not impair mucin O-glycosylation and short-chain fatty acid synthesis in vivo: Implications for gut barrier protection. J. Nanobiotechnol. 2018, 16, 53. [CrossRef] 
99. Paassen, N.B.-V.; Vincent, A.; Puiman, P.J.; Van Der Sluis, M.; Bouma, J.; Boehm, G.; Van Goudoever, J.B.; Van Seuningen, I.; Renes, I.B. The regulation of intestinal mucin MUC2 expression by short-chain fatty acids: Implications for epithelial protection. Biochem. J. 2009, 420, 211-219. [CrossRef]

100. Pinget, G.; Tan, J.; Janac, B.; Kaakoush, N.O.; Angelatos, A.S.; O’Sullivan, J.; Koay, Y.C.; Sierro, F.; Davis, J.; Divakarla, S.K.; et al. Impact of the Food Additive Titanium Dioxide (E171) on Gut Microbiota-Host Interaction. Front. Nutr. 2019, 6, 57. [CrossRef]

101. Chen, Q.; Ren, Y.; Lu, J.; Bartlett, M.; Chen, L.; Zhang, Y.; Guo, X.; Liu, C. A Novel Prebiotic Blend Product Prevents Irritable Bowel Syndrome in Mice by Improving Gut Microbiota and Modulating Immune Response. Nutrients 2017, 9, 1341. [CrossRef]

102. Ye, J.; Lee, J.W.; Presley, L.L.; Bent, E.; Wei, B.; Braun, J.; Schiller, N.L.; Straus, D.S.; Borneman, J. Bacteria and bacterial rRNA genes associated with the development of colitis in IL-10-/-Mice. Inflamm. Bowel Dis. 2008, 14, 1041-1050. [CrossRef]

103. Gokoglu, N. Novel natural food preservatives and applications in seafood preservation: A review. J. Sci. Food Agric. 2019, 99, 2068-2077. [CrossRef] [PubMed]

104. Hrncirova, L.; Machova, V.; Trckova, E.; Krejsek, J.; Hrncir, T. Food Preservatives Induce Proteobacteria Dysbiosis in Human-Microbiota Associated Nod2-Deficient Mice. Microorganisms 2019, 7, 383. [CrossRef] [PubMed]

105. Hrncirova, L.; Hudcovic, T.; Sukova, E.; Machova, V.; Trckova, E.; Krejsek, J.; Hrncir, T. Human gut microbes are susceptible to antimicrobial food additives in vitro. Folia Microbiol. 2019, 64, 497-508. [CrossRef] [PubMed]

106. Cremon, C.; Guglielmetti, S.; Gargari, G.; Taverniti, V.; Castellazzi, A.M.; Valsecchi, C.; Tagliacarne, C.; Fiore, W.; Bellini, M.; Bertani, L.; et al. Effect of Lactobacillus paracasei CNCM I-1572 on symptoms, gut microbiota, short chain fatty acids, and immune activation in patients with irritable bowel syndrome: A pilot randomized clinical trial. United Eur. Gastroenterol. J. 2018, 6, 604-613. [CrossRef]

107. Van Heel, D.A. Interleukin 15: Its role in intestinal inflammation. Gut 2006, 55, 444-445. [CrossRef]

108. Chazelas, E.; Deschasaux, M.; Srour, B.; Kesse-Guyot, E.; Julia, C.; Alles, B.; Druesne-Pecollo, N.; Galan, P.; Hercberg, S.; Latino-Martel, P.; et al. Food additives: Distribution and co-occurrence in 126,000 food products of the French market. Sci. Rep. 2020, 10, 3980. [CrossRef]

Publisher's Note: MDPI stays neutral with regard to jurisdictional claims in published maps and institutional affiliations.

(C) 2020 by the authors. Licensee MDPI, Basel, Switzerland. This article is an open access article distributed under the terms and conditions of the Creative Commons Attribution (CC BY) license (http://creativecommons.org/licenses/by/4.0/). 